\title{
A PALAVRA ROÇADA \\ MEMÓRIA, TRADUÇÃO E NEOBARROCO NA POESIA DE JOSELY VIANNA \\ BAPTISTA
}

Rafael Zacca Fernandes é poeta e crítico literário e é mestre em Filosofia pela Universidade Federal Fluminense, onde escreveu sua dissertação sobre estética e materialismo em Walter Benjamin. Integra o corpo editorial da Revista Chão, onde mantém a coluna Sucesso de Sebo. Participa da Oficina Experimental de Poesia, no Rio de Janeiro.

E-mail: zacca.rafael@gmail.com

\section{Resumo}

Este ensaio procura elucidar a relação do fazer poético da poetisa e tradutora Josely Vianna Baptista com questões históricas e mnemônicas. O livro analisado, Roça Barroca, reúne poemas traduzidos da tradição guarani, considerações a respeito da condição ameríndia, e poemas de autoria de Josely, em um livro multifacetado que se deixa penetrar pelas convulsões sociais que lhe foram legadas.

\section{Resumen}

Este ensayo pretende dilucidar la relación del hacer poético de la poetisa y traductora Josely Vianna Baptista con temas históricos y mnemónicos. El libro analizado, Roça Barroca, reúne poemas traducidos de la tradición guaraní, consideraciones de la condición ameríndia, y poemas de autoría de Josely, en un libro multifacético que deja penetrar las convulsiones sociales que le fueron legadas.

As muitas motivações que originaram $e$ envolvem o mito [da "terra sem mal" dos Guarani] estarão para sempre emaranhadas na memória dos períodos pré-colonial $e$ colonial, nos relatos de viajantes e nas inúmeras análises que se cruzam, se sobrepõem e se contrapõem. Mas o maior mistério a cercar a yvy marã'ey [a "terra sem mal"] talvez seja, afinal, o modo como os Guarani, depois de cinco séculos de opressão, conseguem sobreviver à margem da "barbárie" contemporânea. Olhando a névoa, a nuvem, o orvalho, o alento do roçado em que respira a neblina vivificante, eles vêm mantendo com dificuldade seu tekoha, onde praticam o teko ("modo de ser") de seus antepassados, enquanto buscam preservar, na pouca terra que lhes restou, a natureza e a "fala indestrutivel" (ayvu marã'ey) que os deuses deixaram aos seus cuidados.

Em busca do tempo dos longos sóis eternos, Josely Vianna Baptista, em Roça Barroca.

O cisco no teu olho é a melhor lente de aumento.

(...)

O todo é inverdadeiro.

Theodor Adorno, em Mínima Moralia 


\title{
1) Amor América
}

Quando Neruda escreveu o "Amor America (1400)", poema destinado a abrir o seu grande épico Canto General (1950), ele descrevia um método a partir do qual nos apresentaria uma condição latino-americana.

\author{
Antes que la peluca y la casaca \\ fueron los ríos, ríos arteriales: \\ fueron las cordilleras, en cuya onda raída \\ el cóndor o la nieve parecian inmóviles: \\ fue la humedad y la espesura, el trueno \\ sin nombre todavía, las pampas planetarias. \\ (NERUDA, 2014, p. 1)
}

Munido de ódio contra a história da colonização, que transformou a América em América - que a formou esta e não outra -, Neruda não só regressou sua consciência a uma situação pré-colombiana para entoar o seu canto, como retrocedeu a épocas mais arcaicas que o próprio passado mítico americano. Sua voz buscava a terra ainda sem nome, os rios que a irrigavam, os minerais nela incrustrados, além dos seus bichos selvagens e dos pássaros, graças aos quais "todo era vuelo en nuestra tierra" (Ibidem, p. 7). Perseguir esse momento em que tudo era voo era a sua utopia latino-americana.

Essa utopia insinuava uma procura da magna moralia tropical. Seu método era o da totalidade: por isso precisou recuperar a história dos povos ameríndios e das nações americanas. Seu gesto se assemelhava, como num espelho (reverso e inevitável), ao gesto de Colombo e dos grandes navegadores. Neruda redescobria a América. Isso fez com que o Canto General tenha sido, durante cerca de meio século, um dos livros de maior importância para a possibilidade de emergência de uma consciência "latinoamericana".

É curioso que tenha sido necessário emergir um dos momentos de maior integração a nível global para que uma nova poesia ganhasse tal nível de importância. Afinal, foi justamente essa poesia, gestada no útero temporal da globalização, que engendrou uma nova possibilidade da condição "latino-americana" não a partir do método da totalidade, mas daquele que se dedica à parte mínima. O projeto de Josely Vianna Baptista em Roça Barroca (2011) pode ser definido, em contraposição ao projeto de Neruda em Canto General, como uma mínima moralia dos outros trópicos. Enquanto o poeta chileno nos apresentava sobretudo a terra, para fazer surgir sobre ela seus homens e suas histórias sangrentas, Josely fez surgir de um pequeno broto - ainda que solar - toda a vida dos trópicos. O poema que dá nome ao livro versa também sobre seu método:

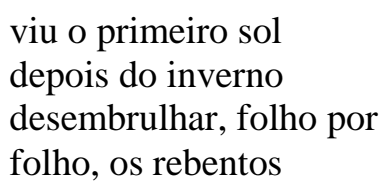

Neruda entoa um canto chileno, cubano, brasileiro, mexicano, guatemalteco... em suma, um canto geral. Josely se satisfaz com o eco de três cantos da tribo dos Mbyá Guarani. É de outro "Amor América" que se trata em Roça Barroca. Se a poesia de Neruda propõe um passado de pleno voo em nossa terra, a poesia de Josely propõe um discreto semear. 


\section{2) Errore}

A arquitetura de Roça Barroca pode ser descrita a partir de duas grandes partes: "Três cantos sagrados dos Mbyá-Guarani" apresenta a tradução desses cantos, além de um "breve elucidário", que comenta os critérios de tradução e a abertura originária das palavras guarani; e "Moradas nômades", que traz poemas autorais. Essas duas partes são prefaciadas por uma nota da autora explicando o percurso da preservação e da tradução dos cantos, e por uma nota do escritor paraguaio Augusto Roa Bastos, com suas impressões da tradução. O livro se encerra com um posfácio do artista plástico Francisco Faria, parceiro de longa data nos projetos de Josely, explicando a dimensão desse trabalho no interior da obra da poetisa.

O cuidado com todos os elucidários e com as notas adverte a "rota sem rumo" do caminho trilhado por Josely. Como tivesse encontrado um antigo mapa, com excesso de imprecisões, fantasias, erros e faltas, a poetisa nos apresenta a sua descoberta com uma série de explicações. Elas exibem todo o universo que se acerca das palavras que reproduzem, em português, os cantos sagrados dos Guarani - e colocam os poemas da poetisa em perspectiva igualmente histórica. São como notas acerca de uma descoberta arqueológica. A condição originária e virgem ameríndia não surge por si própria, e sua auto-exposição é um projeto irrealizável. O poema que inaugura as "Moradas nômades" o adverte:

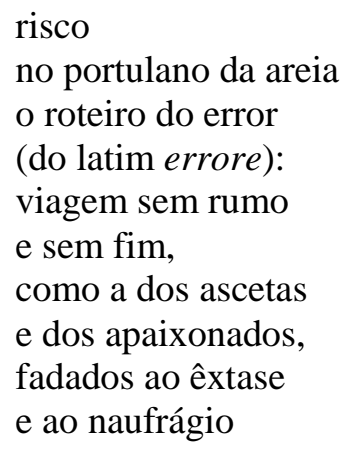

O erro é derivado do "estrangeiro" (o latim). Para dizer o mesmo de outra forma: mesmo a viagem está fadada ao naufrágio. A virgindade da terra e dos homens é inalcançável. A pureza mítica não existe. O que existem são os diários da colonização, a tradição oral dos povos que persistem no tempo, os vestígios materiais de antigos povos e civilizações, e a memória, mais inventora que guardiã do passado. A tradição que se pretende resgatar é repleta de interrupções, seja porque é próprio das tradições uma transformação constante, seja porque no desequilíbrio dos povos sobre a Terra a tradição dos oprimidos é sempre mais brutalmente interrompida que a dos opressores.

Por uma natureza interna e externa, a memória que se pretende resgatar é feita de um todo não coeso e incompleto. Como traduzir, então, os cantos dos Mbyá Guarani? Como movê-los, fazê-los dizer em nossos ouvidos, após tanto tempo e após tanta guerra? Seria necessário um exercício espiritual, para trazê-los? Uma comunhão com o seu conteúdo ideativo por meio de uma ascese divina?

A memória, segundo Siegfried Kracauer, "não engloba nem a totalidade de um fenômeno espacial nem a totalidade do percurso temporal de um fato". (KRACAUER, 2009, p. 67) Para Kracauer, a memória não respeita o ordenamento contínuo dos "fatos": ela destroça o ocorrido para reconfigurá-lo - forma em que um sentido novo 
pode emergir. Apenas nessa distorção um conteúdo de verdade poderia surgir. $\mathrm{O}$ passado surgiria na invenção, não na preservação nem no relato puro do contínuo temporal.

A significação das imagens da memória, diz Kracauer, está acoplada a seu conteúdo de verdade. Na medida em que estão ligadas à incontrolável pulsão vital, habita em seu interior uma ambiguidade demoníaca; imagens foscas como um copo de leite que mal permite passar o brilho da luz. (...) Encontrar a verdade só é possível à consciência liberta que pondera o demoníaco das pulsões. Os traços dos quais se recorda estão em relação com o que se reconhece como verdade, suscetível de se manifestar neles ou de ser deles excluídos.

(KRACAUER, 2009, pp. 67-68)

A condição latina não pode ser perscrutada, para Josely, a partir da recuperação de uma suposta "cronologia natural".

Em primeiro lugar, porque esta é inacessível. As fantasias em torno de uma recuperação do passado "tal qual ele realmente teria ocorrido" são tão ilusórias quanto os filmes de ficção científica onde o herói retorna para verificar o passado com seus próprios olhos. Não apenas a memória é demoníaca, como a própria experiência, que se dá em lampejos.

Em segundo lugar, talvez uma "cronologia natural" não exista. A cronologia é uma das formas de abstração do espaço e do tempo, entre muitas outras possíveis. Ela reconfigura o ocorrido justamente na medida em que retira de seus marcos tudo aquilo que não lhe diz respeito. Cronologia - assim como a cartografia - implica ordenamento e corte, o exato oposto da experiência. Um conto de Borges, traduzido por Josely, torna clara essa oposição, ao relatar o que teria acontecido a um mapa construído com o total da experiência de uma cidade:

Menos Afeitas ao Estudo da Cartografia, as Gerações Seguintes entenderam que esse dilatado Mapa era Inútil e não sem Impiedade o entregaram às Inclemências do Sol e dos Invernos. Nos desertos do Oeste perduram despedaçadas Ruínas do Mapa, habitadas por Animais e por Mendigos; em todo o País não há outra relíquia das Disciplinas Geográficas.

(BORGES, 2008, p. 155)

O projeto de Josely assume essa contradição inerente à construção do passado. Por isso as "Moradas Nômades" começam com poemas que se dedicam a contar a penetração dos portugueses nessa terra. De certa forma, toda poesia tropical é uma redescoberta das Américas. É o caso de poemas como "exercício espiritual" (BAPTISTA, 2011, p. 102) e "anjo da Cia. de jesus" (Ibidem, p. 103), que culminam no desolador "reductio" (Ibidem, p. 105), quando o colonizador, já sem cajado, sem cruz e sem os cordões de veludo, perdido na floresta, revive um sonho:

o berço de menino, o regaço

materno, o abraço proibido

e sua vã memória

converteu-se em

dilúvio

(Idem) 
Apenas ao trair o ocorrido um texto pode fazê-lo ocorrer. Apenas a partir da transmutação da memória da colonização - a qual exige um dilúvio, o mais terrível abalo mítico da civilização cristã que aqui aportou - é possível inaugurar uma espécie de memória tropical. É preciso erguer a memória oficial, para então destruí-la. É com os fragmentos dessa destruição que Josely faz emergir um Outro.

Não é apenas o colonizador que perde sua memória: a primeira morada construída pela Roça Barroca - se a tomarmos como uma espécie de narrativa que nos leva da colonização à recuperação dos cantos de uma vida anterior - que começava por se erguer em frágeis paliçadas, se despedaça por uma reductio inevitável. A vinheta "nenhum gesto / sem passado / nenhum rosto / sem o outro" (Ibidem, p. 109) nos lembra não apenas que em cada gesto e em cada reflexo do presente está a história sangrenta da colonização: ela diz respeito ao método radicalmente histórico de Josely, que não pode alcançar os Guarani sem o destino histórico que deles se apossou.

\section{3) O canto Guarani}

A tradução, em sua ascese ao original, em sua busca incessante do conteúdo de verdade expresso em outra língua, possui uma estreita relação com a memória. Apenas ao aceitar seu destino de perversão do ocorrido, do dito, do escrito, ela é capaz de acessar a chama original: pois se a reescrevesse ipsis literis não seria tradução. Fracassar é o pressuposto para que a atividade da tradução não fracasse. Esse lado demoníaco presente tanto na memória quanto na tradução era bem conhecido de Walter Benjamin, filósofo citado na nota de Josely que introduz a Roça Barroca. O ensaio "Die Aufgabe des Übersetzes", geralmente traduzido por "A tarefa do tradutor", leva no título a palavra alemã Aufgabe, que quer dizer não apenas tarefa, mas também renúncia, abandono. Para Walter Benjamin (2008), o tradutor tem uma tarefa que é ao mesmo tempo uma renúncia. Em outras palavras, o tradutor só traduz ao criar.

$O$ fundamento de qualquer crítica deveria levar em conta esse pressuposto demoníaco da tradução e da memória. Tudo o que é dotado de um poder criador pressupõe o desmonte do original, e a aceitação do fracasso de encerrá-lo em um conceito. A Criação não é um conceito puramente divino, como se supõe - o aspecto demoníaco faz parte da criação mesma, assim como toda religião parte do pressuposto de que algo que deveria estar unido não está, exigindo um método - um rito - para o religar. A memória, a tradução e a crítica (assim como a própria poesia) não se satisfazem com a positividade do conceito e exigem sempre um poder destruidor.

Na compreensão dos Mbyá-Guarani, a linguagem humana possui um vestígio do poder criador. Segundo a explicação de Josely, a palavra ayvu significa linguagem humana, idioma ou fala, e a palavra apyta, base ou origem. O canto "Ayvu rapyta" ("A fonte da fala") trata desse duplo conceito de ayvu como "expressão de ideias" e "porção divina da alma". Segundo o canto:

Namandu, nosso Pai verdadeiro, o primeiro, de uma pequena parte de seu ser-de-céu, do saber contido em seu ser-de-céu, e sob o sol de seu lume criador, alastrou o fulgor do fogo e a neblina que dá vida.

(...) iluminou-se a fonte da fala (...)

e fez com que fluísse por seu ser, divinizando-a.

(BAPTISTA, 2011, p. 31) 
A palavra, do ponto de vista adotado por Josely, é construtora. Mas apenas ao destruir a história oficial, ou seja, apenas a partir do interior da história da colonização, pode fazer brotar o universo dos Mbyá. Universo esse que servirá de base para a condição latino-americana. Essa condição, entretanto, não precisa ser alardeada por Josely. Ela está incrustrada no monograma que a autora constrói, e que carrega consigo um vestígio do poder criador/divino endereçado aos Mbyá por Ñamandu.

A poesia de Roça Barroca se dedica ao material mínimo. Nela, apenas essa matéria ínfima sugere um universal. Em um contexto de hiperglobalização, apenas um nó tenso da grande rede sugere uma imobilização da massa amorfa do geral, para transformá-lo num verdadeiro universal. Ou, nas palavras de um poema sem nome de Josely:

$$
\begin{aligned}
& \text { passo } \\
& \text { após passo: } \\
& \text { antúrios murchos } \\
& \text { no basalto } \\
& \text { lodo } \\
& \text { ou folhedo: } \\
& \text { sobre o restolho } \\
& \text { o couro sangrento } \\
& \text { dos pedregulhos } \\
& \text { na sola } \\
& \text { os talhos } \\
& \text { o solo árduo } \\
& \text { mas alado } \\
& \text { (Ibidem, p. 119) }
\end{aligned}
$$

Apenas o ínfimo é lembrança de voo (o verso que sugere o solo árduo como alado não dá garantias de voo, apenas de asa). Ou, dito de outra forma, na segunda estrofe do "roça barroca":

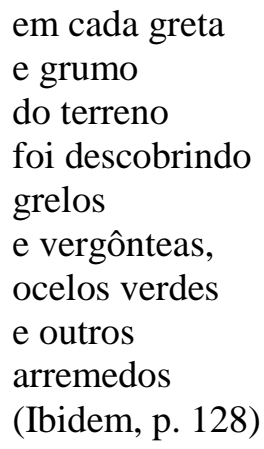

Ao reduzir o escopo de seu olhar para pequenas gretas, grumos, Josely pode ver sucedâneos vitais que não se mostrariam aos olhos que buscam as grandes escalas. É como se a poetisa abrisse fendas, fissuras, não tanto no solo, mas na própria memória coletiva - e, assim, se seguirmos de perto as proposições de Kracauer, na própria história. Os versos de pouco fôlego sugerem o mesmo, em contraposição com o corte (respiração) dos cantos traduzidos. 
Não devemos tomar como gratuita a decisão de por os três cantos traduzidos e registrados ao lado das "Moradas nômades", o conjunto de poemas autorais de Josely. O que impressiona em seu livro é justamente a clareza de seu projeto. Essa clareza apenas aparentemente é ofuscada pela neblina dos parcos dados históricos apresentados e pela abertura da palavra poética: essa cortina de fumaça, como dissemos, faz parte desse mesmo projeto. O poder criador do vestígio, da parte mínima, foi registrado no primeiro canto, "Os primitivos ritos do Colibri":

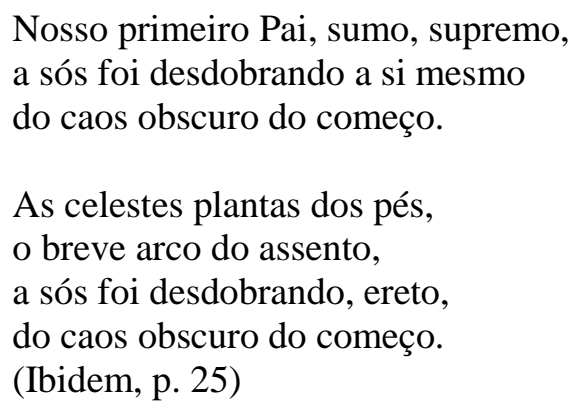

Se tomarmos esse "caos obscuro do começo" não apenas como passado mítico dos Mbyá, mas como nosso próprio passado, como mito originário da condição que nos foi herdada, ${ }^{1}$ a explicação de Josely acerca desse canto ganhará uma força histórica insuspeita:

"Os primitivos ritos do Colibri." Descreve a cena da criação, nos últimos confins do caos obscuro em que Nande Ru Papa tenonde - o deus supremo - foi de si mesmo se desdobrando e se abrindo feito flor. Em meio aos ventos gélidos do tempo-espaço primigênio, quando o Sol ainda não existia e os pios da Coruja sarapintada Urukure'a eram prenúncios do leito tenebroso, em seu desabrochar o deus se entrevê no escuro, iluminado pelo "sol" de seu próprio coração. O Colibri, em adejos sobre a fronte do deus, farta de flores, respinga água em sua boca e o alimenta com frutos do paraíso.

(Ibidem, pp. 10-11)

O terceiro canto guarani, "A primeira Terra", se encerra com uma despedida do pai supremo, que segreda o canto sagrado aos "primeiros pais verdadeiros" de seus filhos, e às "primeiras mães verdadeiras" de suas filhas, garantindo que seja mantida a comunicação entre o divino e o humano. Ele sugere uma força divina em cada filho do pai supremo. Esse sussurro é a voz que Josely busca. Apenas fracassando consegue se assegurar de roçar a superfície sagrada dos cantos, na comunicação entre os Mbyá e todos nós.

De certa forma, Roça Barroca tira outra lição da proposta de Oswald de Andrade, no "Manifesto da Poesia Pau-Brasil", que insinua uma "contribuição milionária de todos os erros." (ANDRADE, 2011, p. 61)

Dito de outra forma, do ponto de vista do colonizador: foi preciso que Colombo acreditasse que viajava para as Índias para que se deparasse com um continente desconhecido por sua civilização. Mesmo nas denominações "índio" e "ameríndio"

\footnotetext{
1 "Latino-americano": o nome da condição pode soar "estrangeiro" aos puristas. Mas o nome das coisas não é direito privilegiado de uns ou de outros. Um nome é uma convulsão histórica. Podemos dizer "condição latino-ameríndia", mas, tentando fugir ao problema, retornaremos assustados às mesmas questões, colocadas de um ponto de vista diferente. O mesmo ocorreria se tentássemos nos denominar com qualquer língua que fosse. Essa é a maior lição das traduções, e por isso o livro de Josely não se intimida ao escrever-se em português.
} 
persiste esse gesto inaugural de "erro" da era das grandes navegações, assim como para os navegantes há sempre um polo magnético que desvia suas bússolas. Walter Benjamin sugeria no seu trabalho das Passagens (2009, p. 499) procurássemos não corrigir o desvio, mas encontrar o polo magnético. As palavras, e o conhecimento, se alimentam desses erros.

\section{4) Neobarroco? A palavra areada e a palavra roçada}

É digno de nota que o poema "roça barroca" não ponha em prática as técnicas do estilo a que denominamos barroco. Se faz uso em uma estrofe de um paradoxo e de algumas aliterações que remetem ao esvaziamento da palavra, não o faz de maneira excessiva de modo a distingui-lo, segundo esse critério, de outros poemas que teríamos classificado como parnasianos, clássicos, etc.

Mais marcante é a aparente ausência do conflito entre o espiritual e o mundano. Mas a ausência só se faz se ignoramos a epígrafe do poema: "As almas são visíveis em forma de sombras." Essa sentença do antropólogo Egon Schaden, dita a respeito da religião guarani, ao decifrar o "barroco" do poema, terá nos fornecido outra chave para a interpretação do livro. A saber, o conflito entre o espiritual e o mundano, ou seja, a desorientação transcendental do poema, que está inscrita na terceira estrofe:

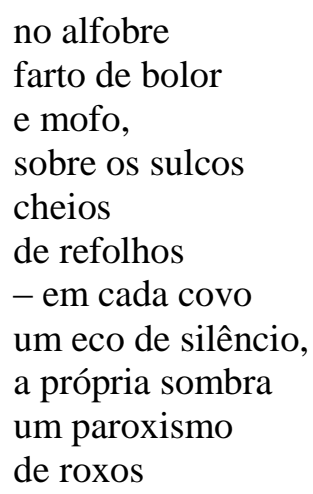

Todos os instrumentos dedicados a armazenar sementes - núcleos duros da vida que se desdobra (quase) de si mesma - nos são apresentados envelhecidos, como signos da finitude, e não da gestação. Mas os refolhos escondem um "eco de silêncio", assim como o mofo abriga as sementes. Aliás, o mofo é ele mesmo um paradoxo do envelhecimento que dá vida a novas formas. Se, segundo a epígrafe que cita Schaden, as almas só são visíveis em sua forma de sombra, apenas ao exibir o paroxismo velado (por pequenos objetos, abrigado em sulcos, frestas, gretas) Josely consegue mostrar o conflito intrínseco a todas as questões espirituais que habitam seu livro.

Pois não é barroco o que não sente certo descompasso com uma metafísica qualquer. É preciso um intenso conflito para que a linguagem entre em crise. O barroco é uma espécie de crise da linguagem. Walter Benjamin (2011) descobriu o conteúdo histórico que desorientou a sociedade que produziu o drama barroco alemão: as lutas religiosas no contexto das reformas e da contrarreforma e os princípios da modernidade fizeram com que a própria palavra entrasse em crise, instaurando um fazer poético alegórico.

No poema intitulado "moradas nômades", o mesmo conflito se apresenta em termos semelhantes ao de "roça barroca": 
pendem do esteio ramos de trigo,

feito amuleto para celeiros cheios;

tachos esfarelam crostas de grãos moídos

e redes balançam seus esgarços,

perto do chão onde uma nódoa preta

mostra o antigo fogo

(BAPTISTA, 2011, p. 130)

Em 1955, Haroldo de Campos previa o surgimento de um neobarroco no Brasil. Escrevia no ensaio intitulado "A obra aberta" que: "Talvez esse neo-barroco, que poderá corresponder intrinsecamente às necessidades culturmorfológicas da expressão artística contemporânea, atemorize, por sua simples evocação, os espíritos remansosos, que amam a fixidez das soluções convencionadas." (CAMPOS, 1975, p. 33)

Haroldo se referia, primordialmente, à "expressão artística contemporânea", que não deveria se tornar uma amante obsessiva da "fixidez das soluções convencionadas". Suas observações são, a princípio, estilísticas. Esta é a interpretação que Augusto de Campos dá à sentença de Haroldo. Ao comentar uma reunião de livros e poemas de Josely, intitulada Sol sobre nuvens, Augusto menciona o ensaio de Haroldo e comenta a palavra "areada" da poeta em livros como Ar. As palavras espaçadas em grandes blocos de "ar concreto" eram interpretadas por Augusto como uma convergência de duas perspectivas: "a das poéticas não-verbais e a da linguagem barroconovista", que compunha um "idioleto verbovisual". (CAMPOS apud BAPTISTA, 2007, Orelha) Esse "estilo" estava em poemas como:

$\begin{array}{ccccccc}\mathrm{n} & \mathrm{a} & & \mathrm{m} & \mathrm{a} & \mathrm{d} & \mathrm{r} \\ \mathrm{u} & \mathrm{g} & \mathrm{a} & \mathrm{d} & \mathrm{a} & & \mathrm{a} \\ \mathrm{g} & \mathrm{u} & \mathrm{d} & \mathrm{a} & & \mathrm{q} & \mathrm{u} \\ \mathrm{a} & \mathrm{l} & & \mathrm{a} & \mathrm{d} & \mathrm{a} & \mathrm{g} \\ \mathrm{a} & & \mathrm{a} & & \mathrm{a} & \mathrm{g} & \mathrm{u} \\ \mathrm{a} & & \mathrm{p} & \mathrm{i} & \mathrm{n} & \mathrm{g} & \mathrm{a}\end{array}$

(BAPTISTA, 2011, p. 15)

Mas Haroldo foi também um crítico que nunca ignorou a história. Se, por um lado, a análise de Augusto não pode ser desmentida, nem desconsiderada, por outro, ela é também incompleta. Em seu ensaio, Haroldo mencionava "necessidades culturmorfológicas". Essa expressão faz crer que a função "artística" das artes é apenas uma entre muitas formas de satisfazer diversas necessidades a que, historicamente, foram destinadas a cumprir. Assim como a palavra areada de Josely merece uma apreciação histórica mais profunda, que corresponda à fluidez e aos espaços vazios, a sua dimensão barroca não pode ser satisfeita com uma análise meramente "literária". O debate proposto por Haroldo coloca a poesia em uma perspectiva muito além do antigo - e hoje um pouco estéril - embate forma x conteúdo. Ele serve de base para novas coordenadas para a interpretação da atividade literária. A poesia de Josely não apenas deve ser desdobrada para além da dualidade forma x conteúdo, como o exige.

A palavra de Josely cuida dos poemas e do material histórico como o roceiro de sua roça. Essa palavra está entre o artesanato do trato individual, ainda não maquinal, do cultivador, e a homogeneização, ainda que mínima, da terra, necessária a qualquer cultivo, por menor que seja, em um roçado.

Em outros termos, Josely não pode mais confiar nem na aliteração gratuita de uma poesia concreta vazia - que tende à homogeneização completa das palavras, reduzidas ao grafismo e ao som -, nem na força do sentido puro. A antinomia desses 
contrários, que não encontra solução, resulta em um eterno roçar. Na medida em que só se roça a terra não plantada, o eterno roçar significa também uma preparação infinita para o semear: daí as sementes mofadas, à espera do plantio. ${ }^{2}$ No impasse entre o som e o sentido, Josely nos apresenta um desabrigo, e em nenhum momento a solução nos é dada.

De que desabrigo falamos? O mesmo de Neruda. A pergunta é simples e antiga: quem somos nós? Neruda respondeu a essa pergunta com menos hesitação, e é admirável que o tenha feito. Sugeria uma solução (aparentemente em outra vida):
Y nacerá de nuevo esta palabra tal vez em otro tiempo sin dolores, sin las impuras hebras que adhirieron negras vegetaciones en mi canto, y outra vez en la altura estará ardiendo mi corazón quemante y estrellado. Así termina este libro, aquí dejo mi Canto general escrito en la persecución, cantando bajo las alas clandestinas de mi patria. Hoy 5 de febrero, en este año de 1949, en Chile, en "Godomar de Chena", algunos meses antes de los cuarenta y cinco años de mi edad. (NERUDA, 2014, p. 532)

A pretensão de totalidade e de acerto são nítidas. O "acerto histórico" no fazer de Neruda se traduziu na precisão da data de sua escrita, como quando verificamos a autenticidade do documento a partir de uma assinatura datada.

Josely, com passos mais curtos, e lâmina afiada, satisfaz-se em carpir o mato da segurança e em nos re-apresentar a pergunta, que no fundo nunca recebeu resposta. Ao imergir no caldo cultural Mbyá, sua palavra roçada universaliza as questões de um povo esquecido por grande parte de seus vizinhos. No poema "guirá ñandu", Josely relê o mito guarani relacionado ao fim do mundo, que diz respeito a uma grande noite, que, não amanhecendo, principiará o desmantelamento da terra:

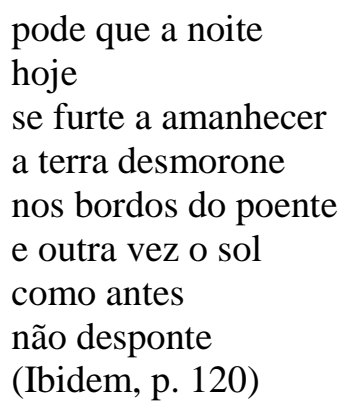

A "longa noite de 500 anos" que se abate sobre a América Latina se faz representar pelo mito Mbyá do fim do mundo. Por que isso transcende o velho debate forma x conteúdo? $\mathrm{Na}$ estrofe estão contidos o mito Mbyá e a história da colonização; nestes, tanto a vida anterior à colonização como a posterior; nessas duas vidas os

\footnotetext{
${ }^{2}$ Devo a ideia da preparação infinita para o semear ao poeta Heyk Pimenta, em conversa privada a propósito do presente ensaio.
} 
conflitos que persistem hoje; assim como no agora podemos perceber todo o decurso das histórias dos diferentes povos.

A poesia se põe a serviço de um aprendizado sutil. Há certo constrangimento em entrar em contato com uma língua que não deveria nos ser estrangeira e que, no entanto, nos é completamente estranha. $\mathrm{O}$ constrangimento diz respeito ao fracasso da memória, ao esquecimento quase irrecuperável de nós mesmos. Em última estância, esse fracasso da memória remete a um fracasso maior: os diferentes povos não se alimentaram mutuamente, e a opressão e o massacre seguem como método diplomático da "civilização".

Entretanto, assim como León Cadogan aprendeu os cantos dos Mbyá-Guarani em um ritual de iniciação, o livro de Josely nos coloca diante de uma iniciação que, surpreendentemente, nos é familiar. Ao perguntar “quem são os Mbyá?", ouvimos Josely perguntar também: "quem somos nós?"

$\mathrm{Na}$ aporia um breve lampejo se insinua:

quem sabe o paraíso que descrevem os antigos não esteja além do vasto nevoeiro e sargaço mas no árduo percurso vencido passo a passo sem bússola ou mapa do céu em pergaminho

talvez além do zênite que ofusca o caminho deixando um invisível roteiro para os olhos que enfrentam o escuro entre os dois crepúsculos

(BAPTISTA, 2011, p. 121)

\section{Referências}

ADORNO, Theodor W. Mínima moralia. Reflexões a partir da vida lesada. Trad. Gabriel Cohn. Rio de janeiro: Beco do Azougue, 2008.

ANDRADE, Oswald de. A utopia antropofágica. São Paulo: Globo, 2011.

BAPTISTA, Josely Vianna. Roça barroca. São Paulo: Cosac Naify, 2011. . Sol sobre nuvens. São Paulo: Perspectiva, 2007.

Walter. A tarefa do tradutor, de Walter Benjamin. Quatro traduções para o português. Belo horizonte: Fale/UFMG, 2008.

UFMG, 2009.

. Passagens. Organizador da tradução brasileira Willi Bolle. São Paulo: 
Autêntica, 2011.

. Origem do drama trágico alemão. Trad. João Barrento. Belo Horizonte:

BORGES, Jorge Luís. O fazedor. Trad. Josely Vianna Batiptista. São Paulo:

Companhia das Letras, 2008.

CAMPOS, Haroldo. “A obra aberta”. IN: CAMPOS, Augusto; CAMPOS Haroldo; PIGNATÁRI, Décio. Teoria da poesia concreta. São Paulo: Duas cidades, 1975.

NERUDA, Pablo. Canto General. [e-book] Versão disponível em http://www.literatura.us/neruda/general.pdf . Acesso em: 20 jun. 2014.

KRACAUER, Siegfried. Ornamento da massa. Tradução de Carlos Eduardo J. Machado e Marlene Houlzhausen. Cosac Naify, 2009. 